\title{
LA DENSIDAD SONORA COMO ALEGORÍA DE LA OSCURIDAD
}

\section{Joaquim Cantalozella Planas}

Universidad de Barcelona, Dpto. Pintura

Transmedia Catalonia Research Group (2014SGR27)

\section{Resumen}

En un sentido metafórico, los dualismos entre luz y oscuridad han dominado prácticamente todas las narrativas que, mediante dicotomías, describen pugnas entre el bien y el mal, lo verdadero y lo falso y, por extensión, lo racional versus lo irracional. En un pensamiento como el nuestro, marcado por lo visual, estos conceptos toman múltiples formas y ramificaciones que, en base a la alegoría, construyen relatos que se afirman en el mito y, en cierta medida, terminan por constituirse en una puerta de acceso a lo oculto. El presente artículo toma por objeto la capacidad del sonido para crear contextos e imágenes que pertenecen a esa realidad desconocida, oscura. En concreto, se analizan tendencias musicales para ver como a partir del ruido evocan lo ininteligible, lo inaudito y la negrura.

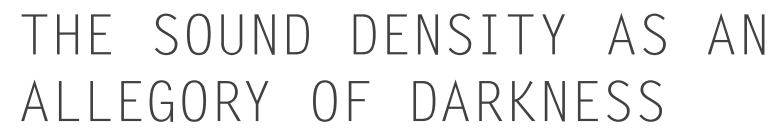

Abstract

At a metaphorical level, the dualism between light and darkness has illustrated practically every artistic account that adopted dichotomies of different kinds to describe the battle between good and evil, truth and falsehood or, by extension, rationality and the irrational. The inherently visual nature of human thought endows these concepts with many shapes and meanings, using allegory to create narratives that are reaffirmed in myth and unlock the doors to a hidden reality. But while the visual is important, this paper takes as its subject the notion that sound can also create contexts and pictures of hidden realities. Specifically, it analyzes musical tendencies which use noise to evoke what is unintelligible, uncommon or otherwise shrouded in darkness.

Key words: MUSIC; NOISE; DARKNESS; TERROR; POLITICS

\footnotetext{
Cantalozella Planas, Joaquim. 2015. "La densidad sonora como alegoría de la oscuridad”. AusArt 3 (2): 162-172. DOI: 10.1387/ausart.15952
}

\section{AUSART}




\section{INTRODUCCIÓN}

El ruido, lejos de enturbiar, proporciona una pátina de significado a la música de la que se extraen narrativas que, en muchos casos, fundamentan ideologías. Con el ruido, la música parece ensombrecerse, se densifica, tanto a nivel perceptivo como en su concepto. El ruido es un sonido sin control de constitución cruda e imprevista, pero si se toma como objeto permite coquetear, simbólicamente, con lo oculto y lo desconocido. En las historias de terror, el ruido suele sugerir una otredad desconocida y amenazante. Dentro de la música, el ruido se puede convertir en una masa de sonoridad capaz apabullar e inquietar al oyente y, a menudo, invocar la negrura.

La alegoría y la metáfora son figuras que parten de imágenes enraizadas en el pensamiento colectivo, cuyas fuentes pueden ser rastreadas. Las metáforas del negro y del ruido habitualmente toman fuerza y coinciden en las subculturas populares. El presente artículo se centra en las relaciones simbólicas entre masas sonoras y negro, o, mejor dicho, entre el ruido y la oscuridad que han calado en nuestras mentes. ${ }^{1}$ Por supuesto, la mayoría de ellas se remontan al dominio de lo visual y poco tienen en cuenta lo auditivo. No obstante, en los últimos tiempos, la música pop ha aumentado su poder político y ha tomado parte en muchas reivindicaciones y transformaciones sociales. Me interesa mostrar, sobre todo, como la convergencia entre el ruido y el color negro despliega un nuevo nihilismo, una religiosidad pagana y blasfema, así como, en sintonía con el terror, una voluntad de producir miedo, puesto que es en éste donde la tiniebla ofrece todo su potencial alegórico.

Para constituir mejor las bases del estudio, primero se analizarán algunos proyectos de la vanguardia musical de mediados del siglo $x x$ que, aunque sean propios de lo que se ha denominado alta cultura, ponen los antecedentes de las posturas más radicales de la música $p o p^{2}$ y experimental.

\section{DEL RUIDO ELECTRÓNICO A LA IMPROVISACIÓN ACÚSTICA}

Habitualmente, el ruido ha sido definido desde la negatividad, pero durante todo el siglo $x x$ se han sucedido movimientos musicales que se han servido 
de él como materia base de sus operaciones. La prioridad para algunos es experimentar los límites del sonido y la música; pero concretamente en los proyectos asociados a la música pop, el ruido sirve para canalizar agresividad y violencia, y así construir una imagen provocadora que sostiene los principios de sus filosofías. Douglas Kahn habla del ruido como aquello que se interpone entre la escucha y lo que se quiere mostrar. Algo que viene definido por su origen y que carga con un significado concreto, que no siempre es posible identificar, lo que remite a la otredad. ${ }^{3}$ Con esto me refiero a que el ruido enturbia su objeto y lo hace de manera imprevista, con algo que no debería estar allí pero que inevitablemente se inmiscuye. Es una pátina que en el momento que niega su objeto introduce coordenadas que aluden a la exterioridad. Por su lado, Paul Hegarty advierte del componente fenomenológico del ruido, puesto que sólo es ruido aquello que identificamos como tal. Es decir, se trata de una reacción negativa a un sonido o a una serie de sonidos que interfieren en nuestra escucha o vida diaria. En un sentido amplio, asegura que el ruido es cultural (Hegarty 2007, 3).

Es desde esta perspectiva que, después de la Segunda Guerra Mundial, los compositores de vanguardia introdujeron el ruido en sus composiciones. El postserialismo, la micropolifonía, la música concreta, la música electrónica o la música aleatoria fueron algunos de los movimientos pioneros en este sentido. Entre los autores, cabe destacar a Karlheinz Stockhausen, Pierre Boulez, Iannis Xenakis, Bruno Maderna, John Cage o Pierre Schaeffer, ya que establecieron las bases para una nueva concepción en la investigación musical. El resultado fue la disolución de las fronteras entre ruido, sonido o música. Estas producciones no eran meros experimentos formales destinados a provocar al espectador; al contrario, se gestaron desde la más pura intelectualidad $y$, en su mayoría, vinieron abaladas por estudios académicos realizados por los propios autores que polemizaban con su tradición inmediata. ${ }^{4}$ Me interesa señalar que pese a su carácter experimental, los temas de corte existencial como la muerte o la vida espiritual permanecieron. Pierre Schaeffer, pionero de la música concreta, la llevó hasta la abstracción y creó, junto con Pierre Henry, una de las composiciones clave de mediados del siglo xx, Symphonie pour un homme seul (1949-1950). También destaco Transamorem-transamortem (1973), obra de Eliane Radigue muy significativa, puesto que toda la composición se basa en tonos de baja frecuencia que se intercambian por los distintos canales de sonido, haciendo que el oyente se desplace lentamente por el espacio sonoro. ${ }^{5}$ No interesa, aquí, la obsoleta discusión en torno a si se trata de música o no, sino percibir la radicalidad en que la sutilidad del sonido se inmiscuye en nuestro cerebro. Otras obras importantes son: Le livre des morts tibétain (1959) y Le livre des morts égyptien (1986-1988), de Pierre 
Henry. Cabe señalar que la música concreta, aunque no tenga nada que ver con ellos, es un precedente claro del noise y el black noise que más adelante analizaré.

Por otro lado, el ruido tiene un evidente componente político que, incorporado a la música, se torna en un síntoma de rebeldía, de lucha y de resistencia. $A$ finales de la década de los setenta, Jacques Attali advertía del poder de la música entendida como domesticación del ruido 6 en el campo político y social. Este aspecto proporciona argumentos para pensar por qué en la música juvenil o popular el ruidismo ha ido en aumento, sobre todo en las escenas underground. Es cierto que el estudio de Attali demuestra desarrollos y estrategias políticas y de poder de la música en general, pero si nos centramos en los movimientos más marginales, se puede ver que el ruido es un arma además de un signo de identidad. Lo curioso, aún así, es ver como en formas más o menos similares da cobertura a luchas de muy distinto carácter. El free jazz de los años sesenta es un ejemplo de ello, donde la cacofonía y la música ruidista sirvieron para exorcizar el malestar de toda una generación. Músicos como Ornette Coleman, Albert Ayler, John Coltrane o Archie Shepp recuperaron el espacio arrebatado a los afroamericanos dentro de la escena del jazz. Se trataba de reafirmar su orgullo y combatir la opresión de la América blanca (Charles \& Comolli 1973, 19-23). El Black Power y otros movimientos afines fueron el sustento ideológico del free jazz; la radicalidad de las acciones políticas se vio de algún modo representada por unas actuaciones que llevaban a su máxima potencia la idea de improvisación. También destaca la espiritualidad y la voluntad de rememorar sus orígenes, queriendo ir más allá de la experiencia humana (Hegarty 2007, 47), como sugieren los trabajos Spiritual Unity (1964), de Ayler; Om (1965) y Interestellar Space (1966), de Coltrane, o cualquier disco de Sun Ra. Es importante ver aquí como, gracias a una instrumentación prácticamente acústica, se consiguen efectos muy cercanos al ruidismo.

Brevemente, quiero añadir que algunos de los músicos que han seguido la estela del free jazz han extremado sus premisas y se han acercado a concepciones mucho más oscuras de la música. Así se puede ver en la obra de Peter Brötzmann y, concretamente, en proyectos como Last Exit, Die Like a Dog o Sonore; en la de Mats Gustafsson, tanto en solitario como en las colaboraciones con Merzbow, Otomo Yoshihide u otros músicos ruidistas; o en la de John Zorn en sus diversas incursiones dentro del noise, y especialmente Naked City, en el que mezcla noise, grind core y jazz, obteniendo unos resultados muy sombríos y siniestros. 


\section{EL NEGRO Y SU RUGIR}

El color negro, como el ruido, ocupa un plano simbólico dominado por la negatividad. Como es sabido, a lo largo de la historia, el negro ha connotado maldad y vacío a partes iguales, ha servido para representar la oscuridad, la muerte, el diablo y las tinieblas, todo ello en clara oposición a la fuerza de la luz, para evocar la verdad y la belleza. El Génesis o la caverna platónica son ejemplos clave para entender el juego de opuestos que se contraponen entre la dicotomía de negro y blanco, luz y oscuridad. Cuando nos referimos propiamente al simbolismo del color, el negro alberga valores positivos y negativos (Pastoureau 2009, 21-42), sus connotaciones se tornan ambivalentes, puesto que la muerte tanto puede ser representada por el blanco o por el negro, lo cual vuelve a suceder con los espectros y otros seres fantasmagóricos. El negro es el color de donde no existe la vida, de todo aquello que nos resulta incomprensible, de lo que está oculto. Como recuerda Michel Pastoureau, el negro "es el color primordial, pero también el que desde sus orígenes posee un estatus negativo: en lo negro la vida no es posible; la luz es buena, las tinieblas no" $(2009,20)$. Desde un punto de vista contemporáneo, no se puede perder de vista como el fascismo y el nazismo utilizaron el negro y, por el contrario, como se reivindica desde la cultura juvenil, puesto que son aspectos que se presentan mezclados dentro de la escena del rock. La luz y la oscuridad son conceptos mucho más arraigados a nuestra conciencia colectiva, y es a partir de ellos que se construyen los grandes relatos. Pensemos en las metáforas sobre la luz que subyacen tras la llustración o, por el contrario, tras las dudas de Nietzsche, el pesimismo de Cioran o la abyección de Bataille, que encarnarían el pensar oscuro que se cierne sobre el proyecto de las luces modernas. Asimismo, dentro de su complejidad, se podrían entender como puertas abiertas a un retorno al pensamiento de lo irracional.

La presencia del ruido en la música tiene que ver con una predilección por sobrepasar los límites, formales y conceptuales, de lo preestablecido. El ruido se encuentra al final de la frontera del sonido, es por definición lo que se descarta como tal. No obstante, se puede decir que el ruido en forma de música, por radical que esta sea, se retrotrae a la normalidad, dado que aquello que era una otredad molesta es asimilado y normalizado, aunque sea mediante el reconocimiento de una minoría. Movimientos como la música industrial, el noise, el grind core o el black metal lo corroboran. Cada uno establece sus propias normas y reglas en la gestión del ruido. Sus diferencias marcan 
las políticas y, en algunos casos, el grado de autenticidad y de pertenencia, como si de una tribu se tratara. Son muchas las propuestas musicales que desde el rock han trazado una concepción plenamente oscura de su obra. Discos como Litanies of Satan (1982), de Diamanda Galas; Only Theatre of Pain (1982), de Christian Death, o Dogs Blood Rising (1984), de Curren 93, son algunos de los trabajos más emblemáticos en torno a este aspecto. Pero, sin duda, la escena del black metal es la más representativa de cómo el uso de masas sonoras electrificadas remite a los objetos más oscuros del ser. Es interesante ver como, en paralelo, se ha desarrollado una tendencia filosófica y crítica llamada Black Metal Theory, que traslada el espíritu que representa el black metal en la música dentro del pensamiento filosófico. En estos estudios heterogéneos se buscan asociaciones entre el black metal y la mística, trazando conexiones con lo indecible. ${ }^{7}$ El black metal es un género que se adentra en la esfera de lo irracional y lo intangible; ${ }^{8}$ el horror es una puerta de acceso. En el llamado culto $(k v / t)$, el mensaje es nihilista y misantrópico $y$, en muchos casos, desemboca en una espiritualidad de la negatividad y de la inversión. ${ }^{9}$ Los conciertos son como rituales adornados con toda clase de objetos profanados. Se trata de puestas en escena que buscan intimidar al espectador transgrediendo los símbolos y, muchas veces, comportamientos morales que fundamentan lo social. Los cantantes ponen al límite sus cuerdas vocales mediante rugidos y voces guturales que parecen catalizar, en un grito existencial, una aflicción extrema que bien podría llamarse cósmica..$^{10}$ Algunas bandas han llevado esta angustia al límite infligiéndose mutilaciones en sus actuaciones en directo, para lograr una unión entre el sonido y el dolor más verdadera. Todo ello presenta analogías con el martirio de los religiosos, que entendían la mortificación de la carne como un camino para llegar a Dios. Así pues, aquello que es propio del cristianismo deviene igualmente natural en las prácticas de quien pretende ser su principal antagonista.

Resulta significativa la predilección de este tipo de grupos hacia la temática religiosa. Por qué un movimiento de adolescentes que empezó en una pequeña tienda de discos a principios de los noventa en Noruega, en la actualidad ha conseguido extenderse por todo el mundo y las bandas se cuentan por millares. Esto indica un interés creciente por unas representaciones que oscilan entre la inversión de la imaginería cristiana, la simbología de religiones antiguas y la estética de la literatura fantástica. En resumen, un combinado que, según se mire, puede resultar aterrador o grotesco, pero que no deja de crecer. 


\section{RUIDO NEGRO}

Los colores del ruido ofrecen datos interesantes para la interpretación. Entre los diferentes tipos que existen (rosa, violeta, marrón, verde, etc.), también se da la bipolaridad entre blanco y negro. El primero toma su nombre de la luz blanca, es decir, posee todos los registros del espectro. Es un ruido que puede ser utilizado tanto para hacer dormir a los bebés como a todo volumen para torturar. El ruido negro sería el silencio y el que gobierna las catástrofes, sean naturales o producidas por el hombre; 11 ambos conllevan matices positivos y negativos.

No son pocos los músicos que han flirteado con el fragor del ruido blanco en sus composiciones. Dentro del subgénero llamado harsh noise, autores como Merzbow o Prurient han radicalizado aún más si cabe la escena del noise; $\mathrm{u}$ otros como Masonna canalizan su radicalidad en furiosas y apasionadas actuaciones que conducen a la catarsis. Algo más matizada es la sonoridad de proyectos black metal como Burzum, Fell Voices o Ash Borer, pues aunque recuerden al ruido blanco, el uso de la melodía y de estructuras marcadas en las composiciones suaviza los resultados. La música de estos grupos parece estar guiada por masas sonoras que se desplazan horizontalmente por el espacio, y debajo de ellas surge la voz, como si ésta estuviera en un plano completamente distinto. Para lo que aquí atañe, los casos más llamativos se encuentran en el subgénero black noise, que es una hibridación entre el noise y el black metal. Generalizando, a nivel temático se mantiene toda la imaginería satánica y de terror, a la que se suman elementos mórbidos, turbulentos y escatológicos. Las técnicas que utilizan de bajo presupuesto ayudan a crear un efecto inquietante, de la misma manera que lo hicieron en los años noventa grupos como Mayhem o Dark Throne. La pérdida de definición produce una mayor agresividad que afecta a los sentidos del oyente y los altera. Con la unión de los dos géneros se intenta sobrepasar sus límites. El ruido, aquí, tiene una evidente significación de muerte, siguiendo a Attali: es desorden, destrucción, suciedad y agresión contra el código que estructura los mensajes (Attali 1977, 54). Es curiosa la ambivalencia semántica del nombre adoptado por este tipo de músicos. El ruido negro, a diferencia del ruido blanco, viene definido por ser un ruido silencioso, plenamente oscuro, pero se puede relacionar igualmente con la náusea y el vacío existencial, como propone Greg Hainge (2013, 67-84). La denominación black noise parece aludir al contenido simbólico de las dos partes y a la advertencia destructora que proviene de la definición física del ruido negro. Se trata de otro caso en que la palabra negro remite más a la acepción cultural que no al término técnico. Pese al nombre 
del subgénero, las producciones de grupos como Gnawl your Tongues, Nahvarl o Stalaggh son próximas al ruido blanco; a ellas se les añaden samplers de voces, ruidos y otros efectos para generar atmósferas opresivas, sórdidas y enfermizas. Otros grupos como T.O.M.B. extraen los sonidos de la realidad, haciendo las grabaciones en lugares donde han ocurrido sucesos terribles, cementerios, iglesias abandonadas o espacios siniestros. Hay una voluntad esotérica que quiere acercarse a lo sobrenatural. De hecho, el proceso y el resultado de estas grabaciones son parecidos a lo que se obtiene mediante las psicofonías. Este método de trabajo recuerda el carácter fantasmal que David Toop atribuye al sonido:

Sound is a haunting, a ghost, a presence whose location in space is ambiguous and whose existence in time is transitory. The intangibility of sound is uncanny - a phenomenal presence both in the head, at its point of source around - so never entirely distinct from auditory hallucinations. The close listener is like a medium who draws out substance from that which is not entirely there, listening after all, is always a form of eavesdropping.

(Toop 2010, xv)

Téngase en cuenta la importancia del aspecto fenomenológico de esta interpretación, puesto que señala otra posible contradicción. Estos grupos despliegan una serie de recursos para rastrear aquello sobrenatural que no percibimos, y para ello utilizan el registro sonoro. Pero las grabaciones neutralizan la presencia de su objeto y aplanan su capacidad de afección, porqué el dispositivo mecánico utilizado filtra, a la vez que codifica, el mensaje. Además, todos los añadidos de sonido, en forma de collage, no hacen más que anular el realismo, situándolos en el lugar de la representación y la fantasía.

\section{UN FILM Y FUNDIDO A NEGRO}

Se han buscado distintas relaciones entre el sonido y el color o, dicho de otra manera, entre lo acústico y lo visual. Los recursos literarios de la metáfora y la alegoría han servido como vehículo para articular el discurso. Sin embargo, el medio que es capaz de reunir sonido, imagen y texto es el cine. Para finalizar, propongo una comparación entre los estilos musicales asociados al black metal y la película Begotten (1991), puesto que puede servir para ilustrar, a nivel visual, la intensidad de la mayoría de temas aquí tratados. 
Aunque no tiene nada que ver con el black metal o el black noise, Begotten es capaz de catalizar en imágenes el espíritu de ambos. Fue escrita y dirigida por E. Elias Merhige, bajo las influencias de las teorías del teatro de la crueldad de Antonin Artaud y la filosofía de Friedrich Nietzsche. Es una película muda y de corte experimental que tiene que ser contemplada como una experiencia transformativa y ritual, según las palabras de su autor. ${ }^{12}$ Se filmó en dieciséis milímetros y contó con un bajo presupuesto. En sus imágenes hay un grano excesivo, provocado por la saturación de la fotografía; es un grano que se convierte en ruido visual y que actúa de la misma manera que lo hacía el ruido acústico en las grabaciones antes citadas. Visualmente, es posible compararla con los clásicos de Friedrich Wilhem Murnau y con esas cintas de los principios del cine, pero debido a su carácter hermético y altamente sugerente, apunta más allá que todas ellas. Begotten es un viaje por los lugares perdidos de la religión. Dios se mata a sí mismo para engendrar a la madre tierra, hechos que devuelven el sentido religioso a versiones muy anteriores del cristianismo. Al igual que el black metal, la película muestra una preocupación por lo religioso, que se encauza mediante una mística violenta que está ensombrecida por el ruido. Ésta es el fruto de un grito nihilista que propone el retorno a una oscuridad que se agita contra el ideario contemporáneo.

\section{CONCLUSIÓN}

Se han intentado relatar diferentes estrategias de como el ruido es capaz de evocar la oscuridad, señalando alegorías y metáforas que toman parte en el proceso. Con ello se han podido ver tres implicaciones importantes: la conexión con el pensamiento de vanguardia y experimental de mediados del siglo $x x$; las posibilidades políticas del ruido, y, por último, un resurgir religioso que se alza desde los márgenes de la música pop mediante un juego de contrarios. El ruido es el vínculo que encontramos entre las tres dimensiones planteadas, así como también lo son, aunque en menor medida, la espiritualidad y/o la religiosidad. El objetivo del estudio ha sido tratar de identificar elementos que, de manera tangencial y a veces subliminal, se inmiscuyen en el campo cultural, condicionando nuestras percepciones y nuestros actos. La principal paradoja la plantean movimientos como el black metal o el black noise, especialmente aquellos que exhiben una actitud plenamente satánica, puesto que, mediante los ataques y las inversiones de la imaginería y creencias cristianas, no hacen más que actualizar su credo y su metafísica. Esto es así, ya que con 
el despliegue sonoro de imágenes y relatos, los mundos profanos o atávicos que se invocan son tratados de la misma forma que se haría en un ritual, pero con los recursos propios de la cultura de masas. En cierto modo se puede vislumbrar la intención de devolver un poder trascendental a la representación recuperando para ella la categoría de verdad, lo que contradeciría la lógica postmetafísica actual.

La música pop pasa a menudo, sin demasiada razón, por ser entendida como algo banal e inocuo propio de la vorágine adolescente, pero hay que tener en cuenta que su área de influencia es enorme, al igual que su capacidad de expansión. Las alegorías que genera el binomio del ruido y la negrura permiten tratar aspectos dentro del debate de la sociedad secularizada, porque recuperan temas que remiten a lugares oscuros del conocimiento y delatan la insistencia de reactivar el pensamiento mítico a través de la música.

\section{Referencias}

Attali, Jacques. 1977. Ruidos: Ensayo sobre la economía política de la música. Valencia: Ruedo Ibérico

Charles, Philippe \& Jean-Louis Comolli. 1973. Free Jazz/Black Power. Barcelona: Anagrama

Hainge, Greg. 2013. Noise Matters: Towards an Ontology of Noise. Nueva York: Bloomsbury

Hegarty, Paul. 2007. Noise/Music: A History. Nueva York: Continuum

Kahn, Douglas. 1999. Noise, Water, Meat: A History of Sound in the Arts. Cambridge, CA: MIT

Lakoff, George \& Mark Johnson. 1986. Metáforas de la vida cotidiana. Madrid: Cátedra

Masciandaro, Nicola. 2015. "Theoria e praxis del Black Metal (Interview by Fabio Selvafiorita for L'Intellectuale Dissidente)". En Mors Mystica: Black Metal Theory Symposium, Edia Connole \& Nicola Masciandaro, eds., 403-11. New York: Schism

Merhige, Elias. 2010. Interview with Elias Merhige 01.31.09. Interview by Scott Essman. Horrornews.net 09/20/2010 http://horrornews.net/13347/intervieweliasmerhigebegotten/

Pastoureau, Michel. 2009. Negro: Historia de un color. Madrid: 451 Editores

Schroeder, Manfred. 1991. Fractals, Chaos, Power Laws: Minutes from an Infinite Paradise. New York: Dover

Thacker, Eugene. 2015. En el polvo de este planeta. Vol. 1: El horror en la filosofía. Madrid: Materia Oscura

Toop, David. 2010. Sinister Resonance: The mediumship of the Listener. Nueva York: Continuum

Wilson, Scott. 2014. "Introduction to Melancology". En: Melancology: Black Metal Theory and Ecology, Scott Wilson, ed. Winchester, UK: Zero Books 
${ }^{1}$ La importancia que tienen las metáforas en la manera como concebimos el mundo, la analizaron George Lakoff y Mark Johnson en su libro, ya clásico, Metáforas de la vida cotidiana.

${ }^{2}$ Entiendo por música pop toda aquélla que deriva del auge del rock'n'roll de los años cincuenta.

3 "The existence of noise implies mutable world through an unruly intrusion of another, an other that attracts difference, heterogeneity, and productive confusion" (Kahn 1999, 22).

${ }^{4}$ Theodor W. Adorno polemizó con la mayoría de esta generación de músicos, como también lo hizo, de forma más virulenta, con el jazz y el rock. Esta posición, con todos sus matices, permite trazar una línea entre lo culto y lo popular dentro de las vanguardias musicales.

${ }^{5}$ http://importantrecords.com/imprec/imprec337.

6 "El ruido es un arma; la música es en primer lugar la formalización, la domesticación, la ritualización de la utilización de ese arma en un simulacro de homicidio ritual, exaltación de lo imaginario" (Attali 1977, 49).

7 "Per me black metal è, soprattutto, una musica spirituale e mistica, fondata sulla negatività dell' essere. Black metal esprime l'essenza negativa della volontà e dunque apre la porta verso l'esperienza incomunicabile, estatica-dolorosa, della realtà che è, eternamente libera e indipendente dai nostri concetti, la realtà divina del che o quodditas infinita" (Connole \& Masciandaro 2015, 404-5).

8 "Evil is this force of measureless expenditure that overwhelms the integrity of individuals and their thought, the very force that black metal, at its finest, invokes in its drive towards sonic ecstasy. In this regard, recourse of mytho-poetic language is necessary to supplement a sonic force which is, of course, entirely a matter of physical form and energy" (Wilson 2014, 12).

${ }^{9}$ Referente a la primera ecuación propuesta por Eugen Thacker, Negro = Satánico: "Si consideramos que el término "black" en el black metal significa satánico, entonces comprobaremos que es el signo propio de una estructura conceptual de oposición (la variante medieval y "herética") y de inversión (la variante "poética" del siglo xIX). En esta vinculación vemos también que el término está a la vez coaligado al mundo natural y a las fuerzas sobrenaturales que residen en él como medios a través de los cuales la oposición y la inversión pueden operar" (Thacker 2015, 26).

${ }^{10}$ La tercera ecuación de Thacker es Negro = Cósmico: "La tercera posición, que podríamos llamar "cósmica", rompe totalmente con esta postura antropocéntrica y afirma una naturaleza "en sí" del mundo, anónima e impersonal, indiferente a nosotros a pesar de todo lo que podamos hacer para cambiarlo, amoldarlo, mejorarlo e incluso salvarlo" (Thacker, 2015, p. 29)

11 "Black noise phenomena govern natural and unnatural catastrophes like floods, droughts, bear markets, and various outrageous outages, such as of electrical power. Because of their black spectra, such disasters often come in clusters" (Schroeder 1991, 122).

12 http://horrornews.net/13347/interview-elias-merhige-begotten/

\section{(Artículo recibido 29-11-15; aceptado 09-12-15)}

